\title{
Other economico-social factors of the saving process
}

\author{
Adriana, GRIGORESCU, \\ Professor PhD, National University of Political Studies and Public \\ Administration, Bucharest, Romania; Associate member of Academy of Romanian Scientists, Splaiul Independentei 54, 050094, \\ Bucharest, Romania \\ adrianagrigorescu11@gmail.com \\ Oana, OPRISAN, \\ Associate Professor PhD, Faculty of Economics, "Ovidius" University, Constanta, Romania \\ oana.oprisan@yahoo.com \\ Elena, CONDREA, \\ Professor PhD, Faculty of Economics, "Ovidius" University, Constanta, Romania \\ elenacondrea2003@yahoo.com
}

\begin{abstract}
Savings and investments are not unconditioned universal ways for the economic development and growth of a country. They accomplish only the motor role in a healthy macroeconomic ambiance, but in the context of a coherent and consistent long-term policy, as well. Only in these circumstances it can become reality the virtuous circle of high savings large investments - economic growth.

For the insuring of the sustainability of the economic growth there will be the need of more effort, which indicates the fact that success is obtainable and that the political efforts in this direction will be rewarded.
\end{abstract}

Keywords: savings; investments; income; wealth

JEL Classification: E2, E20, E21, E22,

\section{Introduction}

Throughout his existence, each individual is confronted with a multitude of problems which may directly affect his existence. The individual, in the context of his existence, can consume a big art of his income with the purpose of gathering reserves for unpredicted situations, in order to leave his children money through a will, to gather money in order to purchase a house or a product with lengthened usage, in order to develop his feeling of independence or just to satisfy a pure greed. All these preoccupations of the individuals and the actions they enterprise on a micro-economical level are under the influence of the state and general evolution of the economy and society.

The analyses on the population's level regarding the saving process go through a series of successive growth, development, interruption and crisis states. The intensities with which they manifest are different from one country to another, from one period to another. The dynamics of the process within the transition from a socialist period to capitalism can be analyzed through the usage of specific concepts, as: economic growth, expansion and recession, development, economical progress and regress etc. Presently, it is considered that the multiplication of the population's savings lead to higher life levels and that is why the saving process represents a major financial politics objective.

The evolutions of the saving process has drawn the attention of an important number of economists who have come up with a multitude of opinions which have lead to the appearing of a 
high number of definitions for this process. Thus, when we reflect upon the notion of saving, the first thought at which we can stop is the fact that it is a constraint, something different from consumption, but, in the same time, a gain, a resulted wealth stock. But, throughout time there has been made a series of theories and models of the saving process which have made obvious the different modes in which the present saving activity influences the future one and identifies the sources which can lead to a continuous growth. Their theories have evolved in time, in function of the dynamics of the economic reality and the evolution of the economic analysis instruments.

In the current context, the saving actually means what has not been invested, and the real saving represents only the support of the general liquidity need for investments; these savings being influenced by a series of subjective and objective factors, general and specific. In essence, we can say that on a global level we are witnessing a growth of the saving bias on the level of the developed countries, as well as at the level of those in transition. Studies show the growth of population savings and the diminishing of their consumption as a result of monetary stabilization (inflation control), price liberalization and the transfer of part of state ownership to private ownership (privatization).

The objective of the paper is to dynamically evaluate the evolution of Romania's saving process analyzing, mainly, the influence of the specific factors on the population's savings, in the transition period, as well as the reasons which stand at the basis of their savings' placement.

The saving's encouraging remains one of the current pertinent intermediary objectives of the economic policy, not only in the purpose of creating better conditions of financing, of capital accumulation, but, also, in the purpose of avoiding of too big a distance between investments and savings.

\section{Investments}

The incline to savings is one of the rational manifestation forms of the human behavior, as is the search of the best valorification method resulted from this process. The motives that determine the individual to save a part of his income are numerous and varied. The phenomenon is of psychological and the determination are always many:

- the fear of an uncertain future;

- the preoccupation of being able to resolve predicted or unpredicted events;

- the wish to have high value goods, which he would not be able to have on the base of the current availabilities;

- the intent of trying to increase the incomes by turning the savings in capital.

The saving process is influenced, also, by a series of subjective or objective factors, factors which have not been contained in the econometric modeling but whose presence has been felt, like the presence of investments. The question of "Why do we need investments?" is posed. The answer: for the inclination towards savings to become a progress factor is necessary that the savings become investments.

In the classic vision, savings precede investments, while for Keynes, they succeed them. The savings do not give birth to investments, but, investments are the ones to contribute to the creation of income and, thus, they generate savings.

In a restraint sense, the investment is a use of the income which materializes in an payment to the capital (or patrimony), to obtain an income.

In a larger acceptance, the investment represents any decision of spending which leads to obtaining an active, with the purpose of ulterior obtaining of a liquidity flux, to increase the wealth of the enterprise's owners. In this context, are assimilated the investments of money transformed in 
physical actives (purchasing buildings, cars, installations, terrains, production stock building). The transformation of money in financial actives represent placing.

The decision of saving and investing, in the case of the small producer, belongs to the same economic agent. He saves and, simultaneously, invests. The volume of the saving of the small producer is measured through the difference between the income and it's consume. He invests in the permitted size of his saving. In this case, he saving and investment are the same. There exists, the identity between the saving and investment motives.

The developed market economies, investments, forming the capital, is effectuated by the non financial societies. When a firm has the possibility to invest, the owner is incited to use an important part of the profit. Thus, the savings of the enterprises depend on the investments they make. The investment is a fundamental economic act, which provokes a future increase of income (from where appears a modification in consume and savings) and, implicitly, lays conditions the size of the production factors use.

The saving process depends on the decisions of each person to give up a profit or a present advantage to a future advantage. Because savings are not destined to the present consume it can be state that their transformation in capital accumulation represents a sacrifice of the population for enjoying a better future consume. Moreover, the saving presumes the safe keeping of the sums owned by the population, while through the investment of the same sums there is expected their multiplication. If we make an abstraction to the available cash, in the house, in the national or foreign, we can consider that the population's savings are invested, because the giving up a present profit through saving is compensated through different ways (dividends, rents etc.).

\section{Population's consume}

As we found out in the anterior sub chapter, the personal incomes of the population represent a positive influence factor on the population's savings, another factor of it, tightly linked to income, is the consume capacity of the population. The size of the population's savings being made obvious by the positive difference between the income of the population the their consume spending.

The consume spending of the population represent the biggest ponder of the demand aggregated in a economy. The acknowledgment of the consume behavior of the population, especially its response to exogenous shocks which affect the determines of the aggregated demand, represent an important source of information for the acknowledgment of the short-term fluctuations and the long-term tendencies which manifest in an economy, including the financial relations with the outside reflected in the payment balance.

From the point of view of financial stability, the focus is now on changes in the evolution and structure of population consumption, in order to capture the possible trends regarding, in particular, the level and dynamics of the indebtedness of the population.

As it is observed in the lower table, the ponder of the population's consume in PIB (medium incline towards consume) has known a growing tendency, in comparison with the minimum point from 2012 (when the growing rhythm of the final consume was inferior to the precedent year, and the net export's contribution at forming the PIB has been positive).

Table 1: The ponder of the population's consume in PIB

\begin{tabular}{llllllll}
\hline & 2008 & 2009 & 2010 & 2011 & 2012 & 2013 & 2014 \\
\hline Medium incline towards consume & 0,832 & 0,830 & 0,789 & 0,785 & 0,772 & 0,779 & 0,794 \\
\hline
\end{tabular}




\begin{tabular}{llllllll}
\hline Marginal incline towards consume & - & 0,828 & 0,702 & 0,726 & 0,726 & 0,808 & 0,853 \\
\hline
\end{tabular}

\section{Source: National Statistic and BNR calculations Institute}

Regarding:

- the exigencies in budget deficit which Romania shall respect in the following years;

- the descendant evolution of the interest rate, as well as

- the tendency of appreciation of the national currency.

It is very possible that the role of the consume (together with that of the investments) will rise in what concerns the PIB forming. This hypothesis is validated and the dynamic of the marginal inclination to consume is, since 2003, superior to the medium one. The conclusion is that the volume of consumption expenditure for the population will increase, perhaps even significantly, by supporting the analysis of the economic behavior of the population in the light of Modigliani and Friedman's theories about the life cycle of saving and permanent income.

In present we admit that the population generally decides his consume and savings going from a vision which englobes all their lifespan:

- from 25 to 45-50 years, the consume tends to be over the income;

- from 50 to 60-65 years, is a period in which the saving capacity is maximum;

- over 60-65 years is the period of retreat from active life, retirement, characterized through a brutal lowering of incomes.

\section{Pension funds}

It should be borne in mind that the savings placed in public pension funds owned property is substituted weak due to low liquidity. Savings made in public pension funds cannot be used before the retirement age, cannot be used as collateral for obtaining bank loans and cannot have a safetysaving function. Thus, the optimum savings of the population should be higher as public pension funds occupy an important share of the pension system.

The actual pension system has represented a safe source of income at the moment of retirements, generating a less acute need for:

- the added fond accumulation in active life, as well as for

- Identifying the market risk utilization solutions related to the amounts saved through the pension fund from the public pension fund.

The reconfiguration process of the current pension system will mainly lead to two preoccupations, which will impose from the authorities, including BNR, the initiation of measures regarding the increase of economic education of the implicated population.

The current pension system, in the conditions in which the number of taxpayers has been significantly outnumbered by the number of beneficiaries, will find itself in difficulty. In this sense are welcomed measured which will urgent the functioning of pylons II and III of private pensions.

\section{Demographic evolution}

From the point of view of financial stability, the second hypothesis raises several concerns, as a number of factors currently address the need for expanding economies. Thus, the demographic evolution from Romania indicate the increase of savings because of an increase of the population's ponder in age is accompanied by the lowering of the savings because the retired population does not make savings or makes them in a more reduced rhythm. In a analog way, a increase of the young 
population ponder but which are not at working age diminish the saving rate because the parents spend a good part of their income on their children.

Figure 1: The demographic pressure of the older and younger population

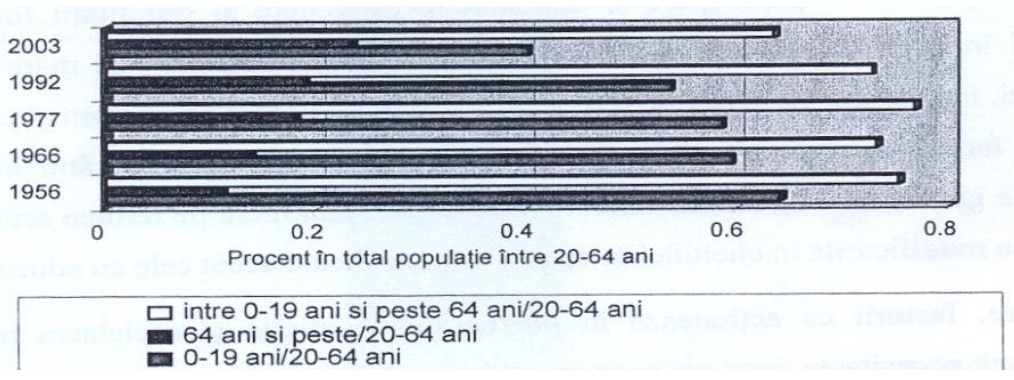

Source: NIS

From fig. nr. 1 we notice a continuous pressure of the older population on the active population, and a lowering pressure of the under 20 population.

Average life expectancy of the Romanian population could be another factor to work towards the need to increase the rate of savings in working life, in order to maintain constant power level for longer.

\section{Population's wealth}

The wealth owned by the population is another factor which influences savings. The wealth's market value can modify as a result of saving behavior modification, or of the modification of prices which make up the fortune. This last effect is registered only for the finance actives component of the population (buildings especially), because the ponder of the population's financial instruments ownership which will bring a income plus as result of the descendant evolution of interest rates is low.

In our opinion for the current situation in Romania, the factor which can significantly stimulate the saving process refers to the liquidities' constraint. This are determined by the necessity of disposing of an advance in the purpose of contraction of a credit for financing the consume. Moreover, the constraints from the crediting process, at which there is added the higher difficulty of obtaining a loan when the economic conjuncture is unfavorable represents other stimulants regarding savings. There must be remarked that this type of savings is temporary, having as purpose a bigger consume. On the other hand, the improvement of the population's access to the resources of financial institutions, beside banks, in the conditions in which they are not held by the same norms of cautiousness like that of the banker sector, can determine an increase of the exposing of the population on these institutions, simultaneously with the diminishing of the need of savings afferent to the liquidity constraints.

Finally, saving money can be an important part of just enjoying life. A trip to Disney World is much more enjoyable when you know that you paid for the trip with money from savings, as opposed to using credit cards to pay for next year's trip.

\subsection{The reason of income}

One of the reason in order to keep the cash constitutes the needs which appear in the period of time among the encashment of the income and his expenditure. The extent to which this reason is in the direction of making a decision to keep a certain amount of money in currency depends in particular on the amount of revenue and the normal duration of the period between the receipt and 
its expenses. This is the issue under which it is proven that the concept of the speed of money circulation in relation to income is correct.

\subsection{The reason of business}

The saving of business supposes the preservation of the cash for the covering of the necessities in the period of time among the effectuation of the expenditures needed of the development of the business and the moment of obtaining the receipts from sales (the retained cash of commercial intermediaries to meet needs in the period between the purchase and sale of the goods is included in this category).

\subsection{Reason of the precaution}

Saving precautionary measures is another reason to keep cash out of willingness to be prepared to be unpredictable, which may require immediate expense, unexpected opportunities (to achieve profitable achievements), and the desire to maintain good value fixed in money, expression for the recovery of a subsequent authorization, also fixed in the monetary expression. Also in this category are long term savings or own professional training of children and saving for old.

The energy of all these three types of mobile phones will depend in part on how cheap and secure the cash-making method is, when one occasion or another occurs during a lending period, especially through the overdraft account of the bank balance or its equivalent. Of course, not necessarily keeping money idle for meeting the needs of different periods of time if they can be obtained without difficulty when they are absolutely necessary.

The presence of precautionary accumulation depends not only on risk but also on risk preferences (Caballero, 1990; 1991) and especially Cagetti (2003). For example, a key factor is the coefficient of aversion to risk (Deaton, 1991) and Carroll (1992; 1996), but available information suggests that there may be substantial differences in this measure between households (Barsky, Kimball, Juster, \& Shapiro, 1997).

Differences in preferences may have other important implications. For example, workers face risks can self-select into occupations (or certain employers in the industry), which provides job security. If risk aversion is positively correlated with caution, these workers can save even more, resulting in a downward trend in estimates reason for precautionary saving (Lusardi, 1997; 2000) and Fuchs-Schündeln \& Schündeln (2005).

The accumulation of caution is strongly affected by the presence of liquidity constraints. To the extent that households can borrow, you may not need so much wealth to protect themselves against shocks. Indeed, saving preventive theoretical models do not provide that wealth will necessarily be (strictly) positive. If households are experiencing differences in terms of lending opportunities, they may want to have different levels of precautionary savings. But individual loan opportunities are indirectly largely unobserved in most data sets.

\subsection{Reason of the speculation}

The speculative saving is the ensemble of the saved incomes used in the opportunities of the plus-valuation in capital (achievements of diamonds, of shares, of houses in the hope to see breeding their price).

As opposed to the reason of transactions and the reason of precaution, as part as the economies represent a resultant of general activity of an economic system and of the level of the 
monetary income, the reason of speculation is that wherewith are acted for the influence of the economically system used in the settlement of the monetary circulation. So, the demand of money for the satisfaction of the first mobiles stays, at generally, insensitive to any type of influences exercised over it, with exception of an effective modification of economic generally activity and the level of incomes. On the other side, the global demanding of money for the satisfaction of speculative reason manifests, usually, continuous reactions to graduated modifications of interest rate. Scilicet, the modifications of demanding of money for the mobile satisfaction of the speculation are bound by a continuous curve of the modifications of instalment of the interest, just as results from the modifications of valuable course of shares and bonds and of the book debts with different term.

In the treatment of speculative mobile is very important to know the distinction between:

- Changes in the interest rate due to variations in the money supply to meet mobile traffic and

- the due of a modifications changes of anticipations which affects the liquidity function.

Open market operations can really influence the interest rate in both directions, as they can change not only the amount of money, but can also cause changes on future-looking policies of the central bank or government.

The changes which appear in liquidity function (pursuant to the apparition of some new information which lead to the resurvey anticipations) shall be frequently discontinuous and shall cause a proper discontinuity of modification of the interest rate. Only in case in which the new information are different interpreted by different persons or affect the individual interests, could increase the volume of transactions on the market of shares and bonds. If the new information affect in exactly the same way the judgement and the requirements of everybody, the interest rate shall can adapt immediately to new situation without being necessarily of an effectuation of some transactions on the market.

Thus, in the simplest case, when everyone has the same features and are in the same situation, a change of circumstances or prediction will not cause any movement of money. It will change the interest rate, to the extent necessary to offset the desire of every person with previous rate of change of the amount held by him in cash, under the influence of new circumstances and expectations and that each of them will change opinion equally on rate that could lead to change cash stock must not generate any transactions. For each pocket circumstances and expectations must match an appropriate interest rate and will never question that someone to change, usually stock cash.

Generally, a change of circumstances or anticipations shall cause a certain reorganization of monetary individual stocks, because effective a such change shall influence in different mode the sights of different individuals, fractionally by reason of a difference in which concerns the environment and the reason for which are kept their money, or by reason of differences in what looks the cognition and the interpretation of the new situation. Thus, the interest rate that corresponds to the new balance will be accompanied by a redistribution of funds.

Therefore, we can say that the purpose of saving all the subjects can have various reasons:

- to protect against riskiness of the life;

- to assure the security of life to old age;

- to generate revenue to cover costs that exceed current income;

- to pay an expense already made under a contracted loan to be returned;

- the enrichment etc. 
Also, to the level of a country could appear at one time excesses of saving up against the expenditures of investments and stocks, case in which this can become an exporter of save up, or otherwise he can become an importer of save up.

The accumulation of debts permits the capitals exports, and the accumulation of assets cause the import of capitals. These debts and obligations can be only consemnated also below monetary form in banks.

Because permanent correlation of revenues and expenses by business entities do not belong to socio- economic reality and the problem of placing income saved during certain periods of time, and the use made in prior periods, in which case the need to use the amount saved.

\section{Conclusions}

Here are four reasons why saving money will help you feel better:

- You can expect unexpected without fear. Emergencies happen with us all - from losing jobs to a hole in the roof. Having an emergency fund brings peace of mind. A nesting egg to cover unexpected expenses can lessen the pain and make you feel capable and responsible.

- You can be ready when you get the chance. Your savings can give you a sense of freedom and independence. If there's an opportunity, you'll have options and chances - to change jobs, move, start a business, invest. The feeling that you have choices can give you a sense of abundance and wealth.

- You can make your dreams come true. One of the best reasons for saving is the exciting experience of building confidence in setting financial goals and achieving them. When you reach a goal, you prove yourself as capable and competent as you really are. You also become a good model for your children looking at you to make sure that life is good and that dreams can be fulfilled.

- You can return with joy. The financial cushion of saving can help you feel confident in your ability to give you back and make a difference in the lives of others. Delivering in ways that are significant to you provides another source of good feelings to improve your life.

We can save to buy things we want when we want, but we can save, because leads us to a life richer, more satisfying and rewarding.

\section{References}

[1] Adelman, I. (1961). Theories of Economic Growth and Development, Standford University Press, Standford.

[2] Anghelache C. (2004). România 2004. Starea economică. Evoluţii semnificative, Ed. Economică Bucureşti.

[3] Beaud, M., \& Dostaler, G. (2001). Gândirea economică de după Keynes, Eurosong \& Book, Bucureşti.

[4] Brăilean, T. (2000). O istorie a doctrinelor economice, Editura Institutului European, laşi.

[5] Bremond J., \& Geledan A. (1995). Diç̧ionar economic şi social, Editura Expert, Bucureşti.

[6] Fisher, S., \& Sahay, R. (2000). The transition Economies after Ten Years, Working Paper No. WP/00/30, IMF.

[7] Carroll C. Fuhrer J., \& Wilcox D. (1994). Does consumer sentiment forecast household spending? If so, why?, American Economic Review, 84, pp. 1397- 1408.

[8] Doms M., \& Morin N. (2004). Consumer sentiment, the economy, and the news media. Federal Reserve Bank of San Francisco, Working Paper 2004-09.

[9] National Commission for Statistics (1996-2015). Issues on quality of life.

[10] National Institute of Statistics (2004-2015). Coordinates of living in Romania. Income and consumption

[11] National Institute of Statistics (2004-2015). The living conditions in Romania, Bucharest.

[12] Negru F., \& Mărgărit, A. (2005). Riscurile pentru stabilitatea financiară din România generate de sectorul populaţiei, Caiete de studii BNR, no. 14, august.

[13] Van de Klundert, T. (2001). Growth Theory in Historical Perspectives, Edward Elgar Publishing, Cheltenham, 2001

[14] Westerhoff F. H., (2008). Consumer sentiment and business cycles: A Neimark-Sacker bifurcation scenario, Applied Economic Letters, Issue 15, pp.1201-1205. 